\title{
Time History Analysis of Concrete Gravity Dam with Gallery and Dam without Gallery by Using STAAD.Pro
}

\author{
Urmila Sarde $^{1}$, A.P.Jaiswal ${ }^{2}$ \\ ${ }^{1}$ Post Graduate Student Structural Engineering, Shreeyash College of Engineering and Technology, \\ Aurangabad. \\ ${ }^{2}$ Professor, Department of Civil Engineering, Shreeyash College of Engineering and Technology, Aurangabad.
}

\begin{abstract}
Concrete Gravity Dams are important lifeline structures and represent the fragrance of people's standard of living. Dam structures that span navigable waterways are inherently at a risk for seismic vibrations and as such they must be designed to resist these vibrations. These are very complex structures and subjected to various types of forces both static and dynamic in nature. However, these earthquake vibrations are fundamentally dynamic in nature and a static analysis procedure may not be adequate in designing hydraulic structures like Dam. This paper presents the dynamic time history analysis of a concrete gravity dam by using STAAD-PRO. Here Finite Element Approach is used to analyze the dam. A concrete gravity dam model is prepared in STAAD-PRO to perform the time history analysis and a comparison is done between dam with gallery (i.e openings) and dam without gallery (i.e openings).Seismic analysis is performed for both dam with gallery (i.e openings) and dam without gallery (i.e openings). Various basic loads and load combinations are used in analysis of concrete gravity dam according to IS 6512:1984 Table 1 represents basic loads and load combinations used during the analysis.
\end{abstract}

Keywords: Concrete Gravity Dam, Time History Method, Stress Contour, IS Code 6512:1984, STAAD-PRO.

\section{Introduction}

Basically, a gravity dam is defined as a structure, which is designed in such a way that its own weight resists the external forces. It is primarily the weight of a gravity dam which prevents it from being overturned when subjected to the thrust of impounded water. This type of structure is durable and requires very little maintenance. The two general concrete construction methods for concrete gravity dams are conventional placed mass concrete and RCC. However, concrete gravity dams are preferred these days and mostly constructed. They can be constructed with ease on any dam site, where there exists a natural foundation strong enough to bear the enormous weight of the dam. Such a dam is generally straight in plan, although sometimes, it may be slightly curve. The line of the upstream face of the dam or the line of the crown of the dam if the upstream face in sloping, is taken as the reference line for layout purposes etc. and is known as the "Base line of the Dam" or the "Axis of the Dam". When suitable conditions are available, such dams can be constructed up to great heights.

A Concrete Gravity Dam is a Solid Structure which takes care of all external forces simply by its own weight, shape and strength of concrete. These are complex structures and are subjected Static Type of loads viz., Dead loads, Reservoir and Tail water loads, uplift pressure, Earth and silt pressures etc.and Static Type of loads viz., Seismic forces, Wind forces etc. Seismic forces on structures depend largely on the ground motions during the earthquakes. The response of a dam subjected to seismic loading, exhibits a combined effect of the interaction among dam, reservoir and foundation systems. Hence, there is a significant importance in studying the various aspects influencing the seismic response of a large concrete gravity dams for safe and long lasting service to public domain. The magnitudes of maximum compressive/tensile stress at the heel/Toe/any other planes normal to the faces of the dam rapidly change and huge variation in stresses can be observed during the earthquakes.

Hence, a paramount importance is gained for the dynamic seismic stress analyses with finite element procedures to obtain a clear insight into the response behavior of concrete gravity dams. The main aim of this study highlights on the response behavior of dam with gallery (i.e openings) and dam without gallery (i.e openings) with effect of foundation flexibility and reservoir interaction under the static and dynamic seismic forces.

\section{The main objectives of the present study are}

- A comparative study of Dynamic seismic analysis for maximum Compressive and Tensile stresses at Heel /Toe/ in dam body for the various load combinations for, "dam with gallery and dam without gallery".

- To visualize the stress contours pattern and distribution under various load combinations. 
Time History Analysis of Concrete Gravity Dam with Gallery and Dam without Gallery by Using

II. Parametric Details Of Model

2.1. Specification of Models for $60 \mathrm{~m}$ height of the dam with gallery.

\begin{tabular}{|l|l|}
\hline Type of Structure & Concrete gravity dam \\
\hline Seismic Zone & II, As per IS 1893 (Part I)-2002, Z=0.10 \\
\hline Importance Factor & For all dams=3 \\
\hline Rock and Hard soil Site Factor & medium Soil = 1 \\
\hline Damping Ratio & 0.05 \\
\hline Height of the dam & $60 \mathrm{~m}$ \\
\hline Length of dam & Unit length of dam is considered. \\
\hline Size of gallery & $4 \mathrm{mX} 4 \mathrm{~m}$ \\
\hline Depth of foundation & $120 \mathrm{~m}$ \\
\hline Base width of dam & $48 \mathrm{~m}$ \\
\hline Specific weight of Concrete & $25 \mathrm{kN} / \mathrm{m}^{3}$ \\
\hline Poisson ratio of Concrete & 0.17 \\
\hline Modulus of elasticity of Concrete & $21.718 \mathrm{~N} / \mathrm{mm}^{2}$ \\
\hline
\end{tabular}

2.2. Specification of Models for $60 \mathrm{~m}$ height of the dam without gallery.

\begin{tabular}{|l|l|}
\hline Type of Structure & Concrete gravity dam \\
\hline Seismic Zone & II, As per IS 1893 (Part I)-2002, Z=0.10 \\
\hline Importance Factor & For all dams = 3 \\
\hline Rock and Hard soil Site Factor & Hard Soil =1 \\
\hline Damping Ratio & 0.05 \\
\hline Height of the dam & $60 \mathrm{~m}$ \\
\hline Length of dam & Unit length of dam is considered \\
\hline Depth of foundation & $120 \mathrm{~m}$ \\
\hline Base width of dam & $48 \mathrm{~m}$ \\
\hline Specific weight of Concrete & $25 \mathrm{kN} / \mathrm{m} 3$ \\
\hline Poisson ratio of Concrete & 0.17 \\
\hline Modulus of elasticity of Concrete & $21.718 \mathrm{~N} / \mathrm{mm} 2$ \\
\hline
\end{tabular}

2.3. Specification of Models for $60 \mathrm{~m}$ height of the dam without gallery.

\begin{tabular}{|l|l|}
\hline Type of Structure & Concrete foundation \\
\hline Rock and Hard soil Site Factor & Hard Soil =1 \\
\hline Damping Ratio & 0.05 \\
\hline Depth of foundation & $120 \mathrm{~m}$ \\
\hline Specific weight of Concrete & $25 \mathrm{kN} / \mathrm{m} 3$ \\
\hline Poisson ratio of Concrete & 0.17 \\
\hline Modulus of elasticity of Concrete & $21.718 \mathrm{~N} / \mathrm{mm} 2$ \\
\hline
\end{tabular}

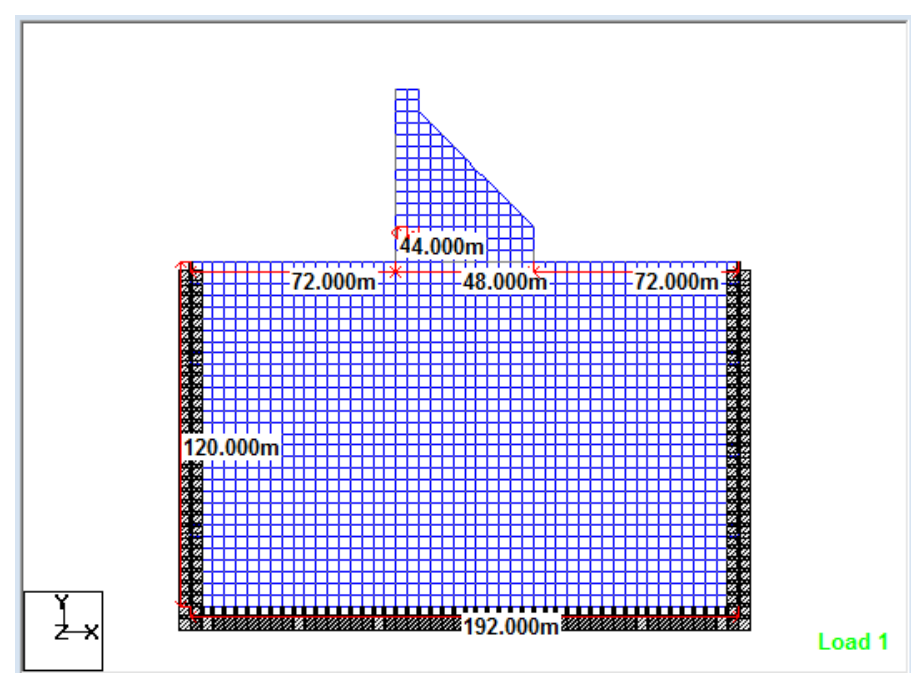

Fig.1: Finite Element Model of the Dam with gallery (openings) 


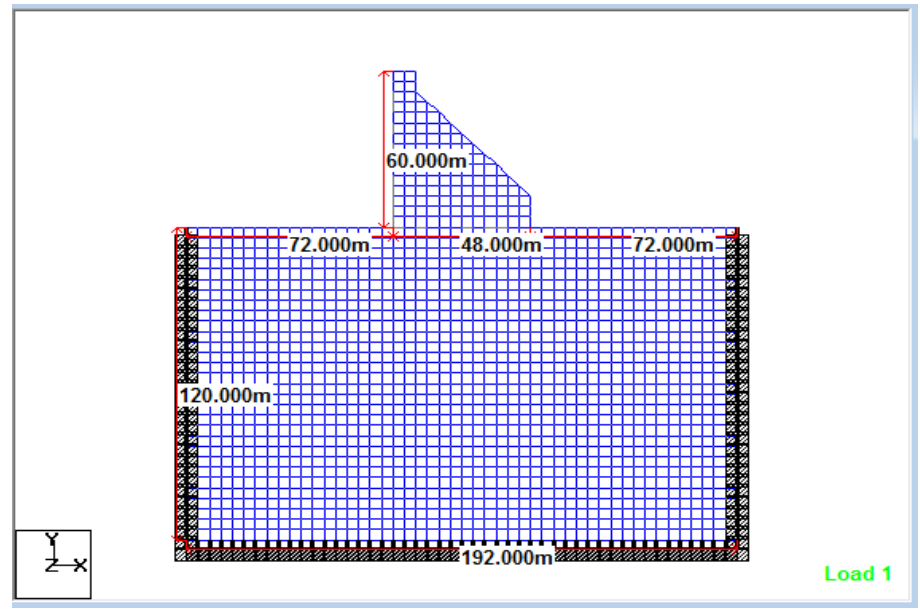

Fig.2: Finite Element Model of the Dam without gallery (openings)

\section{Methodology}

This paper presents the dynamic time history analysis of a concrete gravity dam with gallery (i.e openings) and gravity dam without gallery (i.e openings) by using STAAD-PRO. A concrete gravity dam of heights $60 \mathrm{~m}$, is prepared in STAAD-PRO to perform the time history analysis. Finite element has been widely used in the analysis of concrete gravity dams with a defined approach as presented in this paper. Time history is basically a method of seismic analysis for the simulation of an earthquake motion. It is an ultimate tool to study the dynamic response of a structure. In this paper stresses at heel and toe of Dam with gallery and Dam without galley are analyzed by Time history method for Various basic loads and load combinations according to IS 6512:1984.

\section{1 .Finite element modeling of the dam}

The dam body is modeled in STAAD pro using the solid isoparametric finite elements with eight nodes.as shown in above fig .1 and fig .2. Each node has three translational degrees of freedom. The stiffness matrix of the solid element is evaluated by numerical integration with eight Gauss - Legendre points. The dam is analyzed for several basic loads and load combinations possibly met with during its analysis. These are enlisted in table 1 below. The stresses induced are checked for all the combinations.

Table 1: Basic loads and load combinations used during the analysis.

\begin{tabular}{|l|l|}
\hline Sr.No & Basic loads and load combinations \\
\hline 1 & Self weight of dam (DL) \\
\hline 2 & Water pressure (WP) \\
\hline 3 & Tail water pressure (TWP) \\
\hline 4 & Silt pressure (SP) \\
\hline 5 & Uplift pressure (UP) \\
\hline 6 & Earthquake pressure (EQL) \\
\hline 7 & Time history loads (TH) \\
\hline 8 & (DL + WP+TWP + SP + UP + EQL + TH) \\
\hline
\end{tabular}

\section{Results And Discussion}

Table 2: Comparison of stresses between Dam with gallery and Dam without gallery

\begin{tabular}{|c|c|c|c|c|c|c|c|}
\hline \multirow{2}{*}{$\begin{array}{l}\text { Sr. } \\
\text { No }\end{array}$} & \multirow[t]{2}{*}{ output } & \multicolumn{3}{|c|}{ Solid centre stress } & \multicolumn{3}{|c|}{ Solid corner stress } \\
\hline & & $\begin{array}{l}\text { Normal stress } \\
\text { in } \mathrm{N} / \mathrm{mm}^{2}\end{array}$ & $\begin{array}{l}\text { Shear stress } \\
\mathrm{N} / \mathrm{mm}^{2}\end{array}$ & $\begin{array}{l}\text { Principal } \\
\text { stress } \\
\mathbf{N} / \mathbf{m m}^{2}\end{array}$ & $\begin{array}{l}\text { Normal } \\
\text { stress } \\
\mathbf{N} / \mathbf{m m}^{2}\end{array}$ in & $\begin{array}{l}\text { Shear } \\
\text { stress } \\
\text { N/mm }\end{array}$ & $\begin{array}{l}\text { Principal } \\
\text { stress N/mm } 2\end{array}$ \\
\hline 1 & Dam with gallery & -28.626 & 14.517 & -25.073 & -24.940 & 14.18 & -28.71 \\
\hline 2 & Dam without gallery & -35.527 & 18.469 & -28.996 & -32.337 & 18.18 & -30.71 \\
\hline
\end{tabular}




\subsection{Response results of dam}

4.1.1. Model 1: Dam with gallery

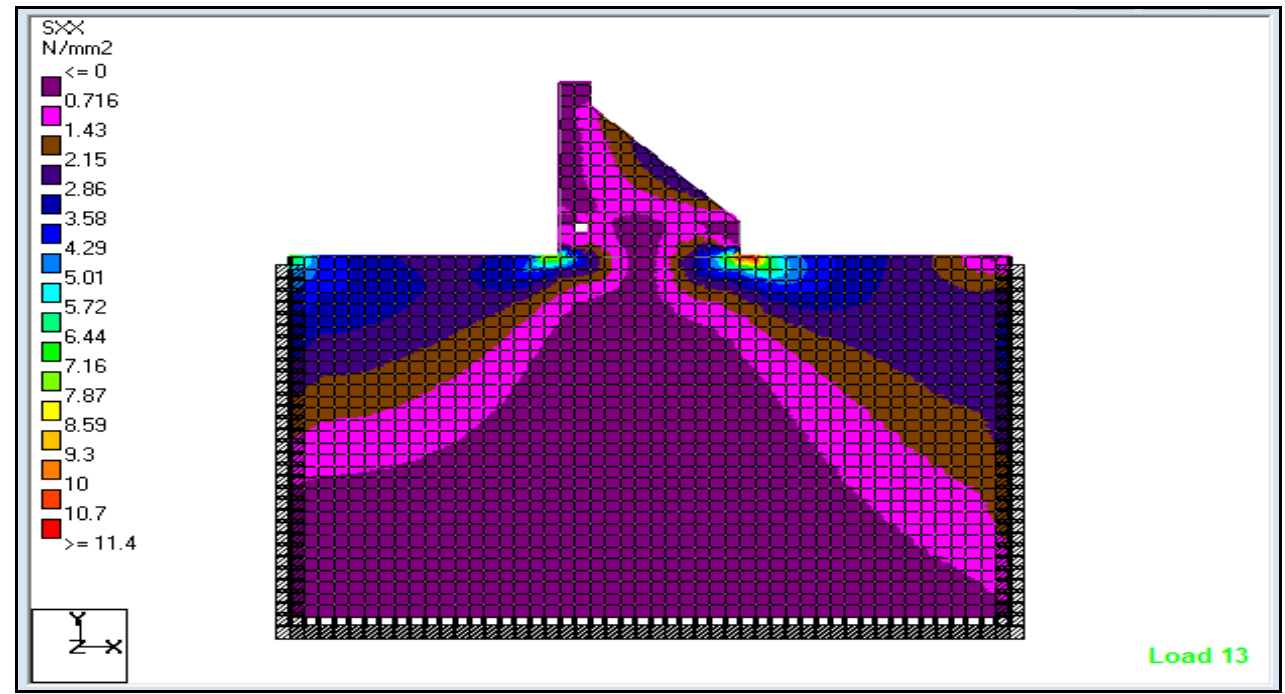

Fig.4: Stress diagram for Dam with gallery

4.1.1. Model 2: Dam without gallery

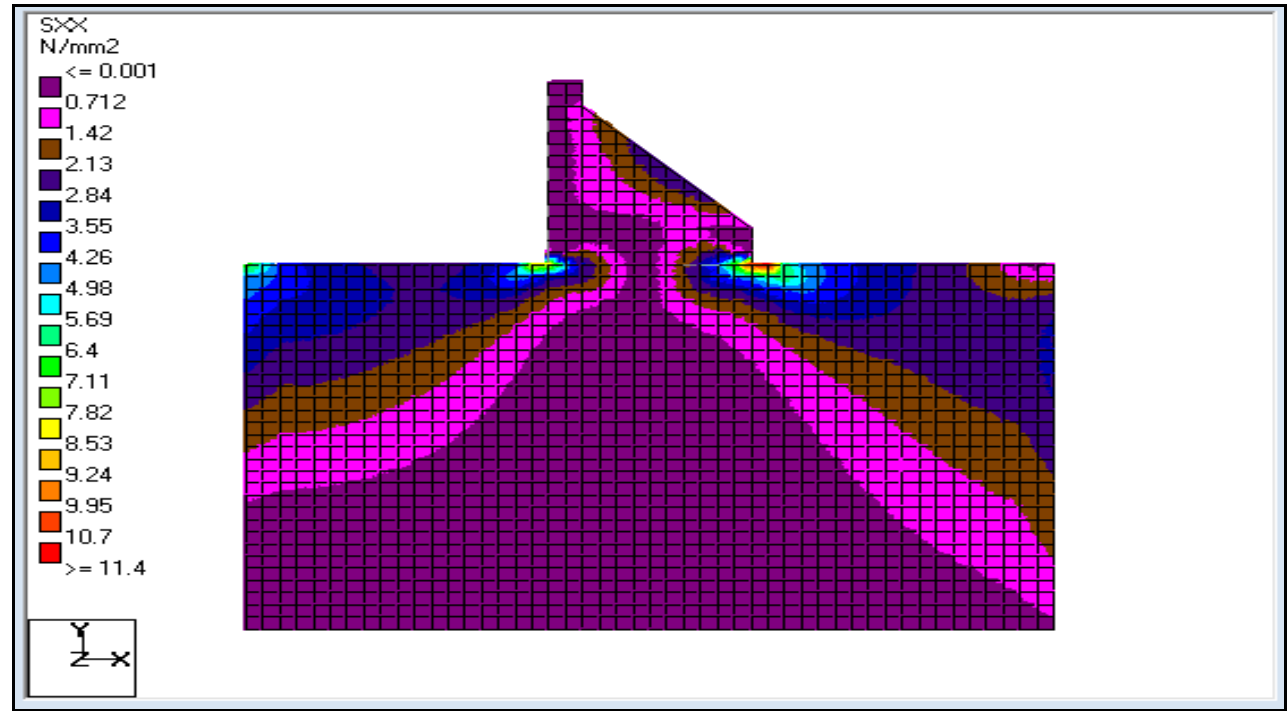

Fig.5: Stress diagram for Dam without gallery

\section{Conclusions}

The Conclusions from above study are as follows

a) The compressive and tensile stresses at heel /toe of the Dam with gallery are less as compare to Dam without gallery.

b) The main advantage is that stress variation through the dam body can be studied carefully and the slopes can be designed according to the stress pattern..

c) From the response of dam we can conclude that there is effect in stress variation in the dam due to the construction of gallery.

d) STAAD-PRO is the most convenient and less tedious for dynamic analyses and it provides a computing environment to investigate modelling assumptions and computational processes related to the static and seismic structural stability of gravity dams. 


\section{References}

[1]. Rohan kulkarni (2015) "Non-Linear Time History Analysis of Concrete Gravity Dam by Using SAP2000”International Journal of Innovative Research in Science, Engineering and Technology (An ISO 3297: 2007 Certified Organization) Vol. 4, Issue 4, April 2015 .

[2]. Pratik Patra (2014) "Development of Methology for Seismic Design of Concrete Gravity Dam" , B.Tech Thesis, National institute of technology Rourkela.

[3]. Chagantipati Tanooja, (2016) "Design of Gravity Dam by using Seismic Coefficient Method in Different Zones", International Journal for Technological Research in Engineering Volume 4, Issue 4, December-2016.

[4]. Kaushik Das, (2011) "Seismic Response of Concrete Gravity Dam”, HTC 2011.

[5]. Joshi S.G (2015) "Analyzing the Effect of Foundation Inhomogeneity on the Seismic Response of Gravity Dams" International journal of civil and structural engineering volume 6, no 1, 2015.

[6]. karim m pathan,(2012), "Finite Element Analysis of 99.60 m High Roller Compacted Concrete (R.C.C) Gravity Dam - Special Emphasis on Dynamic Analysis" International journal of civil engineering and technology (ijciet).

[7]. Aarti Baburao Rampure,(2016 "Dynamic Time History Analysis and Response Spectrum Method of a Concrete Gravity Dam by using STAAD-PRO”, Open Journal of Civil Engineering, 2016, 6, 329-334.

[8]. T Subramani (2012) "Seismic and Stability Analysis of Gravity Dams Using Staad PRO "International Journal of Engineering Research and Development ISSN: 2278-067X, Volume 1, Issue 5 (June 2012), PP.44-54.

[9]. Dr. K. Rama Mohan Rao (2014), "Finite Element Modelling and Seismic Response Evaluation of Large Concrete Gravity Dams An Approach based on Indian Standard Codal Guidelines", International Journal of Emerging Engineering Research and Technology Volume 2, Issue 2, May 2014, PP 178-186.

[10]. N.P. Gahlot , (2014) , “Seismic Analysis for Safety of Dams ",IOSR Journal of Mechanical and Civil Engineering(IOSR-JMCE) eISSN: 2278-1684,p-ISSN: 2320-334X, Volume 6, Issue 3 (May. - Jun. 2013), PP 42-47.

[11]. Jay P. Patel (2015) "Analysis of Concrete Gravity Dam by 3D Solid Element Modeling using STAAD-Pro", IJSTE - International Journal of Science Technology \& Engineering | Volume 1 | Issue 11 | May 2015 ISSN (online): 2349-784X.

[12]. I.S.6512-1984, "Criteria for Design of Solid Gravity Dams". B.I.S. New Delhi.

[13]. I.S.1893-1984, "Criteria for Earthquake Resistant Design of Structures". B.I.S. New Delhi 